\title{
Valorization of lignin and cellulose in acid-steam-exploded corn stover by a moderate alkaline ethanol post-treatment based on an integrated biorefinery concept
}

\author{
Sheng Yang ${ }^{1}$, Yue Zhang ${ }^{1}$, Wen Yue ${ }^{2}$, Wei Wang ${ }^{3}$, Yun-Yan Wang ${ }^{4}$, Tong-Qi Yuan ${ }^{1 *}$ and Run-Cang Sun ${ }^{\text {* }}$
}

\begin{abstract}
Background: Due to the unsustainable consumption of fossil resources, great efforts have been made to convert lignocellulose into bioethanol and commodity organic compounds through biological methods. The conversion of cellulose is impeded by the compactness of plant cell wall matrix and crystalline structure of the native cellulose. Therefore, appropriate pretreatment and even post-treatment are indispensable to overcome this problem. Additionally, an adequate utilization of coproduct lignin will be important for improving the economic viability of modern biorefinery industries.

Results: The effectiveness of moderate alkaline ethanol post-treatment on the bioconversion efficiency of cellulose in the acid-steam-exploded corn stover was investigated in this study. Results showed that an increase of the alcoholic sodium hydroxide $(\mathrm{NaOH})$ concentration from 0.05 to $4 \%$ led to a decrease in the lignin content in the posttreated samples from 32.8 to 10.7\%, while the cellulose digestibility consequently increased. The cellulose conversion of the $4 \%$ alcoholic $\mathrm{NaOH}$ integrally treated corn stover reached up to $99.3 \%$ after $72 \mathrm{~h}$, which was significantly higher than that of the acid steam exploded corn stover without post-treatment (57.3\%). In addition to the decrease in lignin content, an expansion of cellulose I lattice induced by the $4 \%$ alcoholic $\mathrm{NaOH}$ post-treatment played a significant role in promoting the enzymatic hydrolysis of corn stover. More importantly, the lignin fraction (AL) released during the $4 \%$ alcoholic $\mathrm{NaOH}$ post-treatment and the lignin-rich residue (EHR) remained after the enzymatic hydrolysis of the $4 \%$ alcoholic $\mathrm{NaOH}$ post-treated acid-steam-exploded corn stover were employed to synthesize lignin-phenol-formaldehyde (LPF) resins. The plywoods prepared with the resins exhibit satisfactory performances.
\end{abstract}

Conclusions: An alkaline ethanol system with an appropriate $\mathrm{NaOH}$ concentration could improve the removal of lignin and modification of the crystalline structure of cellulose in acid-steam-exploded corn stover, and consequently significantly improve the conversion of cellulose through enzymatic hydrolysis for biofuel production. The lignin fractions obtained as byproducts could be applied in high performance LPF resin preparation. The proposed model for the integral valorization of corn stover in this study is worth of popularization.

Keywords: Corn stover, Acid-steam-explosion, Alcoholic NaOH, Post-treatment, Enzymatic hydrolysis, Lignin, Ligninphenol-formaldehyde resin, Biorefinery

\footnotetext{
*Correspondence: ytq581234@bjfu.edu.cn; rcsun3@bjfu.edu.cn

1 Beijing Key Laboratory of Lignocellulosic Chemistry, Beijing Forestry

University, Beijing 100083, People's Republic of China

Full list of author information is available at the end of the article
} 


\section{Background}

The depletion of fossil fuel resources and ever-growing greenhouse gas has resulted in an increasing worldwide interest in alternative nonfossil-based sources of energy $[1,2]$. At present, governments across the globe are committed to identifying new clean energies to power the world's future with sustainable supply capacity and low- or zero-carbon emissions. Bioethanol, a fuel produced from lignocellulosic biomass, is largely considered a favorable potential alternative to fossil fuels $[1,2]$. The conversion of lignocellulosic biomass to bioethanol involves the hydrolysis of cellulose to monosaccharides, and then the fermentation of these sugars into ethanol. Enzymatic hydrolysis is a key step in the ethanol production from low-cost lignocellulosic materials [3, 4]. Due to compactness of lignocellulose matrix and the crystalline structure of the native cellulose $[5,6]$, pretreatment is necessary to disrupt the recalcitrant matrix to make the cellulose more accessible to the enzymes, which convert carbohydrate polymers into fermentable sugars [7]. These pretreatment technologies can be classified into biological, physical, chemical, and physicochemical methods, including dilute acid, steam explosion, hot-compressed water, organosolv, ammonia fiber explosion, and aqueous lime or alkali pretreatments [8-13]. All of the pretreatment methods have limitations; therefore, the synergistic benefits of combined methods should be considered [14].

Acid steam explosion (ASE) is one of the most extensively studied pretreatment methods, which opens the compact lignocellulosic plant cell walls and effectively removes most of the hemicelluloses, consequently increases the efficiency of cellulose hydrolysis $[15,16]$. The acid-steam-exploded residues are mainly composed of cellulose and lignin. Particularly, it is well known that lignin limits the digestibility of lignocelluloses [17-19]. Therefore, a delignification process is essential for the biomass before it is subjected to enzymatic hydrolysis. It should be noted that the lignin in the corn stover has been partially degraded and deposited on the surface of the treated corn stover during the ASE process [20]. Thus, just relatively mild post-treatment may be needed to eliminate the remaining lignin fraction in the lignocellulosic biomass for promoting the subsequent enzymatic hydrolysis. However, the reports about such study are rare.

$\mathrm{NaOH}$ solution has been reviewed to be efficient in dissolving lignin, and causes lignocellulosic biomass to swell leading to an increase in the internal surface area under relatively mild conditions, thus it enhances the enzymatic hydrolysis of lignocellulosic biomass [21, 22]. Ethanol has been widely used in lignocelluloses treatment as a solvent for increasing the dissolution of the degraded lignin fractions [23]. After the removal of ethanol, the obtained high concentration lignin solution can be directly used to prepare other chemicals or materials without any further treatments. In fact, in addition to the high concentration lignin solution, a large amount of lignin-rich residue is also recovered after enzymatic hydrolysis and fermentation. From the economic point of view, many cellulosic ethanol demonstration plants have attempted to integrate their key technologies into processes including the pretreatment of raw materials, hydrolysis, fermentation, distillation, and waste treatment [24]. For these reasons, the effectiveness of the mild alkaline ethanol post-treatment of the acid steam exploded materials in terms of an integrated biorefinery process would be a quite worthwhile research object.

The main purpose of this study was to investigate the effectiveness of the moderate alkaline ethanol post-treatment on the enzyme hydrolysis efficiency of cellulose in ASE technology. The post-treated samples obtained were subjected to composition analysis and characterized by Fourier-transform infrared (FT-IR), solid-state cross polarization/magic angle spinning (CP/MAS) ${ }^{13} \mathrm{C}$-NMR spectroscopy, and X-ray diffraction (XRD). The analysis results were used to evaluate the factors affecting enzymatic hydrolysis. The lignin samples obtained from the moderate alkaline ethanol post-treatment were analyzed and applied to synthesize lignin-phenol-formaldehyde (LPF) resin, and the applicability of lignin-rich residue in LPF resin synthesis was also evaluated. A potential model for integral valorization of corn stover will be proposed in this study.

\section{Results and discussion}

\section{Compositional analysis}

The acid-steam-exploded corn stover was post-treated with alkaline ethanol with different $\mathrm{NaOH}$ concentrations, and an acid sodium chlorite post-treated acid-steamexploded corn stover was also obtained as a comparison (an extensively delignified sample). In Table 1, all the samples have been identified by the different post-treatment methods used. The compositions of untreated corn stover, acid-steam-exploded corn stover, the post-treated samples, and the solid yields of each post-treated samples are given in Table 1. As compared with the composition of untreated corn stover (36.5\% cellulose, 22.1\% hemicelluloses, and $18.8 \%$ lignin), the ratio of relative content of cellulose to lignin slightly decreased in the acid-steamexploded materials (Sample 1) due to the significant degradation of hemicellulose during the steam-explosion process. In addition, this phenomenon also implied that the compact matrix of plant cell wall has been significantly modified and some of the cellulose has been degraded during the ASE treatment. The accessibility of cellulase to cellulose could be significantly improved, and the conversion rate of cellulose should also increase [25]. However, 
Table 1 Compositional analysis of the untreated, acid-steam-exploded and integrally treated corn stovers

\begin{tabular}{|c|c|c|c|c|c|c|}
\hline Samples & Treatment methods & Solid yields & Cellulose & Hemicelluloses & Lignin & Others \\
\hline Corn stover & Untreated & - & $36.5(2.1)$ & $22.1(0.9)$ & $18.8(1.7)$ & $22.6(1.3)$ \\
\hline 1 & Acid steam explosion & - & $55.6(3.5)^{a}$ & $5.7(0.7)$ & $32.8(2.6)$ & $5.9(0.9)$ \\
\hline 2 & $\begin{array}{l}\text { Acid steam explosion followed by a } 0.05 \% \text { alcoholic } \mathrm{NaOH} \\
\text { post-treatment }\end{array}$ & 78.1 & $71.1(2.8)$ & $6.4(0.6)$ & $19.1(3.4)$ & $3.4(0.6)$ \\
\hline 3 & $\begin{array}{l}\text { Acid steam explosion followed by a } 0.5 \% \text { alcoholic } \mathrm{NaOH} \\
\text { post-treatment }\end{array}$ & 70.3 & $78.9(3.3)$ & $4.2(0.6)$ & $15.9(3.2)$ & $1.0(0.1)$ \\
\hline 4 & $\begin{array}{l}\text { Acid steam explosion followed by a } 4 \% \text { alcoholic } \mathrm{NaOH} \\
\text { post-treatment }\end{array}$ & 65.4 & $84.0(4.4)$ & $4.1(0.7)$ & $10.7(1.7)$ & $1.2(0.8)$ \\
\hline 5 & Acid steam explosion followed by a $\mathrm{NaClO}_{2}$ post-treatment & 59.6 & $89.2(2.5)$ & $7.5(1.1)$ & $3.0(0.4)$ & $0.3(0.1)$ \\
\hline
\end{tabular}

a The value in parenthesis is standard deviation

as shown in Table 1, lignin, which limits the digestibility of lignocelluloses, remains in the acid-steam-exposed corn stover in a relative content of $32.8 \%$. In the integrated corn stovers treatment, the ratio of cellulose to lignin increases dramatically as the $\mathrm{NaOH}$ concentration increases. Generally, the gradual removal of lignin was accompanied with the increase of conversion of cellulose [26]. At $4 \%$ concentration of $\mathrm{NaOH}$ (Sample 4), the relative content of cellulose reached up to $84.0 \%$ with only $10.7 \%$ lignin remained in the post-treated sample. To this effect, alkaline ethanol post-treatment under the mild conditions was proved to be a very effective delignification method. Sample 5 , which was post-treated with acid sodium chlorite, had the lowest lignin content (3.0\%) and highest cellulose content (89.2\%) among the five samples. Such treatment may result in the highest cellulose conversion rate in this study, yet other factors may also contribute to the cellulose conversion result, and they need to be considered.

The relative proportions of hemicelluloses of the five samples listed in Table 1 (4.1-7.5\%) did not vary much from one another as compared to the changes in cellulose and lignin. Therefore, the influence of hemicelluloses on sugar yield can be ignored in this work. It should be mentioned that only xylose in hemicelluloses was lost during the post-treatment process. A series of alkaline ethanol with different $\mathrm{NaOH}$ concentrations were processed to obtain various degrees of delignification, but only three are displayed in Table 1 . It should be noted that lignin content presented a gradient decrease (32.8-10.7\%) within the four post-treated samples (Sample 1-4) which may be an ideal series to investigate the effects of lignin content on the enzymatic hydrolysis of cellulose in the subsequent studies.

\section{FT-IR spectra}

The FT-IR spectra of the acid-steam-exploded corn stover and the post-treated samples are shown in Fig. 1. The bands at 1597, 1510, and $1429 \mathrm{~cm}^{-1}$ are corresponding to aromatic skeletal vibrations, and $\mathrm{C}-\mathrm{H}$ deformation combined with aromatic ring vibration was found at $1451 \mathrm{~cm}^{-1}[27,28]$. In Samples 1-4, the four characteristic absorption peaks of lignin became gradually weaker as the $\mathrm{NaOH}$ concentration increased. These four peaks almost disappeared in Sample 5, which was post-treated with acid sodium chlorite. Correspondingly, gradual increase of intensities of the bands at 1198 and $1156 \mathrm{~cm}^{-1}$ corresponding to $\mathrm{O}-\mathrm{H}$ stretching and $\mathrm{C}-\mathrm{O}-\mathrm{C}$ vibrations at $\beta$-glucosidic linkages in cellulose were observed. These phenomena altogether indicated that the relative contents of cellulose in Samples 1-5 increased due to the increasing removal of lignin. The FT-IR results obtained above were all in reasonable agreement with the compositional analysis (Table 1). Additionally, a new peak at $1731 \mathrm{~cm}^{-1}$, which is assigned to non-conjugated carbonyl groups [29], appeared in the spectrum of Sample 5 , which was probably that the oxidation of the cellulose occurred during the process of acid sodium chloride delignification.

\section{CP/MAS ${ }^{13} \mathrm{C}$-NMR spectra}

To further investigate the structural characteristics of the acid-steam-exploded corn stover and the post-treated corn stovers, all the samples were subjected to $\mathrm{CP} /$ MAS ${ }^{13} \mathrm{C}$-NMR spectroscopy analysis. The corresponding spectra are depicted in Fig. 2. The region between 55 and $110 \mathrm{ppm}$ was dominated by strong signals assigned mostly to various cellulosic carbons, and the sharp signal at $104.7 \mathrm{ppm}$ is attributed to the ordered cellulose $\mathrm{C}-1$. The signals at $68-80 \mathrm{ppm}$ are due to cellulose $\mathrm{C}-2$, $\mathrm{C}-3$, and $\mathrm{C}-5[30,31]$. The relative intensity of the signal at $56.0 \mathrm{ppm}$, which corresponds to the methoxyl groups $\left(-\mathrm{OCH}_{3}\right)$ of aromatic moieties in lignin, decreased as the $\mathrm{NaOH}$ concentration increased until nearly disappearing entirely in the spectrum of Sample 5. Analogous results have been reflected in the compositional and FT-IR analyses discussed above. 


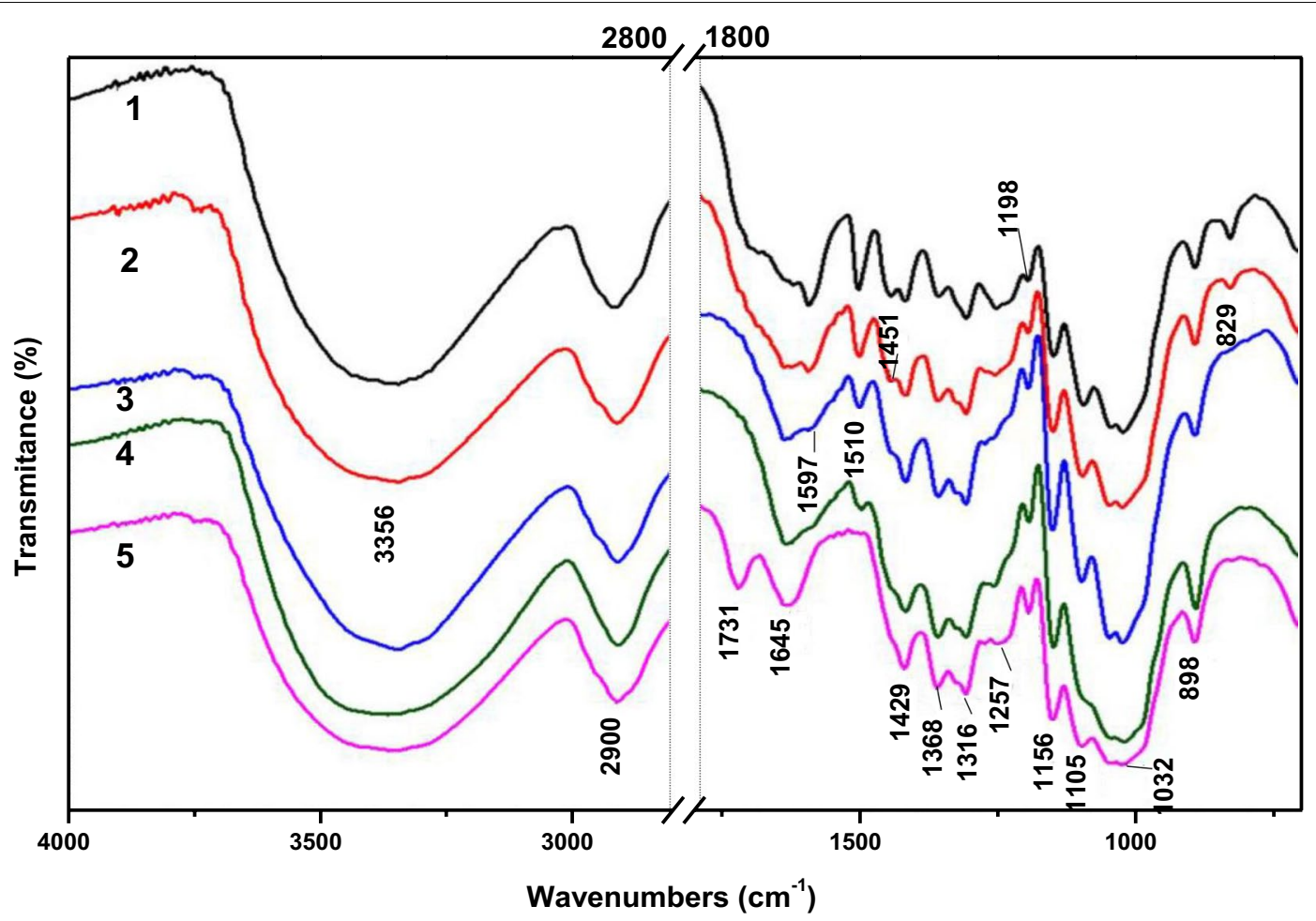

Fig. 1 FT-IR spectra of the acid-steam-exploded and the integrally treated corn stovers

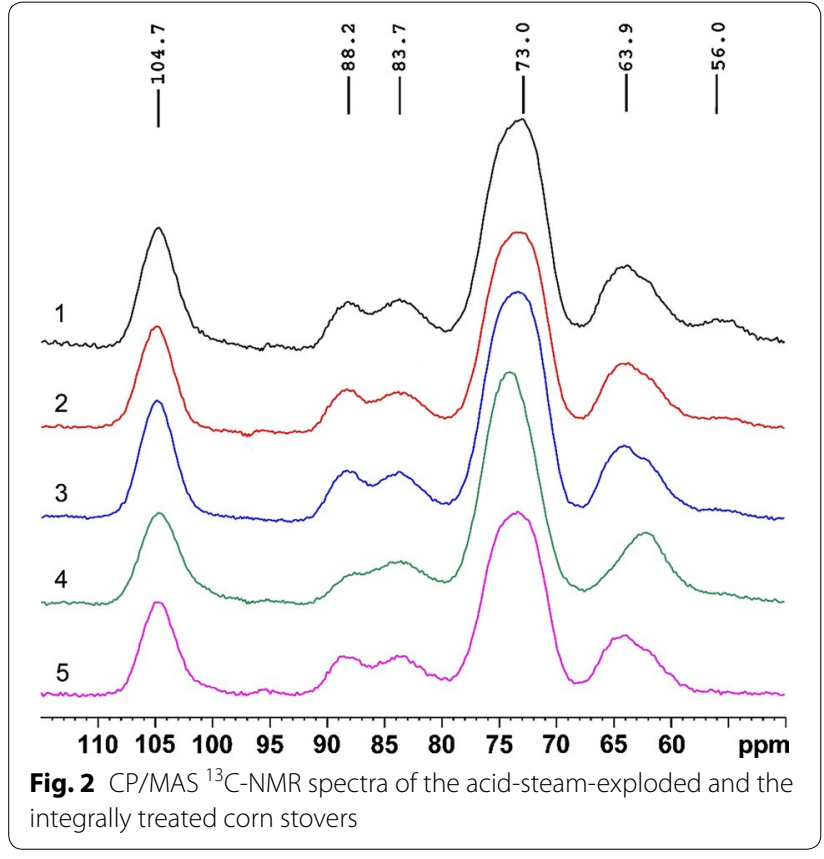

Obvious signals for amorphous and crystalline carbons of cellulose could be detected. The chemical shifts at 88.2 and $63.9 \mathrm{ppm}$ are ascribed to crystalline cellulose
C-4 and C- 6 carbons, respectively. The signal at $83.7 \mathrm{ppm}$ is due to amorphous cellulose C-4 carbons, and the signal at $62.2 \mathrm{ppm}$ is attributed to amorphous cellulose C-6 [32]. In Sample 4, which was delignified with $4 \%$ alcoholic $\mathrm{NaOH}$, the intensity of the signal at $88.2 \mathrm{ppm}$ decreased and increased at $83.7 \mathrm{ppm}$, respectively. The peak at $63.9 \mathrm{ppm}$ seemingly disappeared and shifted to $62.2 \mathrm{ppm}$ in Sample 4, but the peaks at 63.9 and $62.2 \mathrm{ppm}$ coexisted in Samples 1-3 and 5. This indicated that part of the cellulose structure of Sample 4 transformed from the original crystalline cellulose into amorphous cellulose. The amorphous cellulose is more vulnerable to cellulose enzymes and thus favors glucan conversion [33]. It should be noted that the signal at $63.9 \mathrm{ppm}$ in the spectrum of Sample 4 should not be completely disappeared. The intensity of this signal in Sample 4 was weak and overlapped with other signal due to the poor resolution of the NMR method used. In Sample 5, both of the crystalline signals 88.2 and $63.9 \mathrm{ppm}$ have not shifted. It seems that the crystalline domain of cellulose was not disrupted by acid sodium chlorite post-treatment.

\section{XRD analysis}

Cellulose crystal structure is considered one of the major substrate properties influencing biomass enzymatic digestibility [33]. In this study, the 
acid-steam-exploded corn stover and the post-treated samples were examined by XRD to gain insight into the potential structural features affecting cellulose hydrolysis (Fig. 3). The crystallinity index $(\mathrm{CrI})$ values of Samples 1-5 were calculated to be 47.6, 48.9, 50.7, 42.4, and $52.8 \%$, respectively. The slight increase of $\mathrm{CrI}$ in Samples 1-3 was due to the gradual removal of amorphous lignin and hemicelluloses with alkaline ethanol. While for Sample 5, it was due to the removal of lignin with acid sodium chlorite. All these four samples exhibited typical diffraction patterns of cellulose I, the main peak of which lies near $22.5^{\circ}$ and the secondary broad peak at $\sim 16.0^{\circ}$. In fact, the broad peak at $\sim 16.0^{\circ}$ should be consisted of two small peaks at $15.2^{\circ}$ and $16.8^{\circ}$, but the XRD analysis conditions used make it hard to be distinguished as reported by Trache et al. [34]. In Sample 4, conversely, the shape of diffractogram and trend of $\mathrm{CrI}$ differed notably as compared to other samples. The main peak around $22.5^{\circ}$ was weakened and shifted slightly to a lower angle, and there was no peak at $12.1^{\circ}$ (one of the typical diffraction patterns of cellulose II). These results confirmed that the cellulose in Sample 4 was in a transition status from cellulose I to cellulose II, and that an expansion of cellulose I lattice occurred. It has been reported that this benefited the conversion of cellulose to glucose [35]. It is important to note, however, that $4 \%$ aqueous $\mathrm{NaOH}$ post-treatment alone under similar conditions would not lead to the same results [35]. It may be due to that the solubility of lignin in $4 \%$ alcoholic $\mathrm{NaOH}$ was higher than that in $4 \%$ aqueous $\mathrm{NaOH}$. Thus, the exposed surface area of cellulose in $4 \%$ alcoholic $\mathrm{NaOH}$ was more than that in $4 \%$ aqueous $\mathrm{NaOH}$, and the cellulose I lattice was easy to be expanded under such moderate condition.

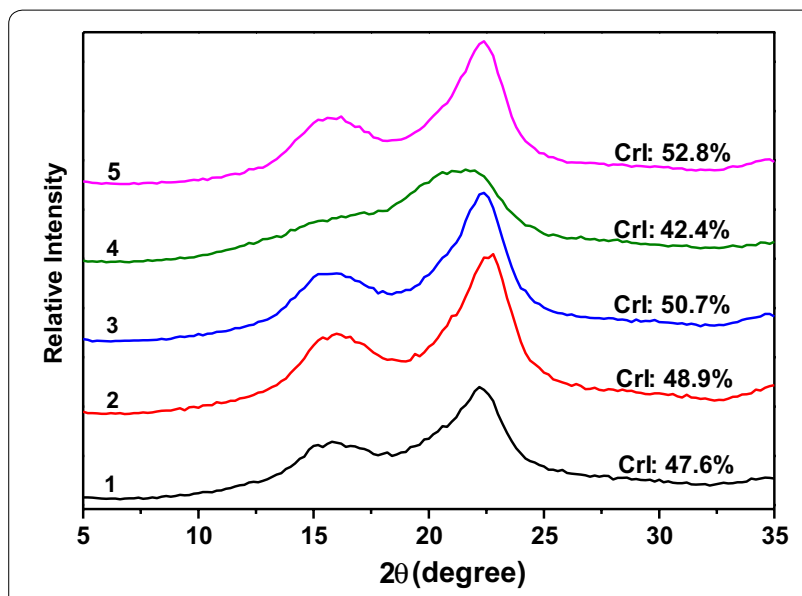

Fig. 3 X-ray diffractograms of the acid-steam-exploded and the integrally treated corn stovers

\section{Enzymatic hydrolysis}

To evaluate the effects of different post-treatment conditions on glucose yield, the enzymatic hydrolyses of the acid-steam-exploded corn stover and the post-treated samples were comparatively studied as shown in Fig. 4. Cellulose digestibility was $57.3 \%$ for the only acid-steamexploded material (Sample 1) within $72 \mathrm{~h}$ enzymatic hydrolysis, and for the post-treated Samples 2, 3 and 5, the glucose yield was $64.3,76.7$, and $92.7 \%$, respectively. The corresponding lignin contents of Samples 1-3 and 5 were $32.8,19.1,15.9$, and $3.0 \%$, respectively. These results indicated that the efficiency of enzymatic hydrolysis was significantly affected by the remaining lignin content, and it increased as the lignin content decreased. In general, cellulose conversion is known to decrease as the $\mathrm{CrI}$ of cellulose increases, and it has been already reported that the $\mathrm{CrI}$ is related to cellulose content or alfa-cellulose [31]. However, this phenomenon was not observed in the data of Samples 1-3 or 5 in this study. This indicated that the content of lignin in the lignocelluloses is also a very important factor affecting the rate of enzymatic hydrolysis except for the crystallinity of the material. As the lignin content decreased in the sample, the rate of the enzymatic hydrolysis increased. In addition, the results of compositional analysis indicated that the cellulose in the acid-steam-exploded corn stovers was not obviously removed during alkaline ethanol post-treatment. Most of the alfa-cellulose remained in the post-treated samples, and its relative content increased as a result of the removal of amorphous components (lignin and hemicelluloses). Only a slight removal of non-crystalline cellulose may be occurred during the process.

It was interesting that the cellulose digestibility of Sample 4 reached a maximum of $99.3 \%$ after 72 h, higher than that $(92.7 \%)$ of Sample 5 despite its relatively high

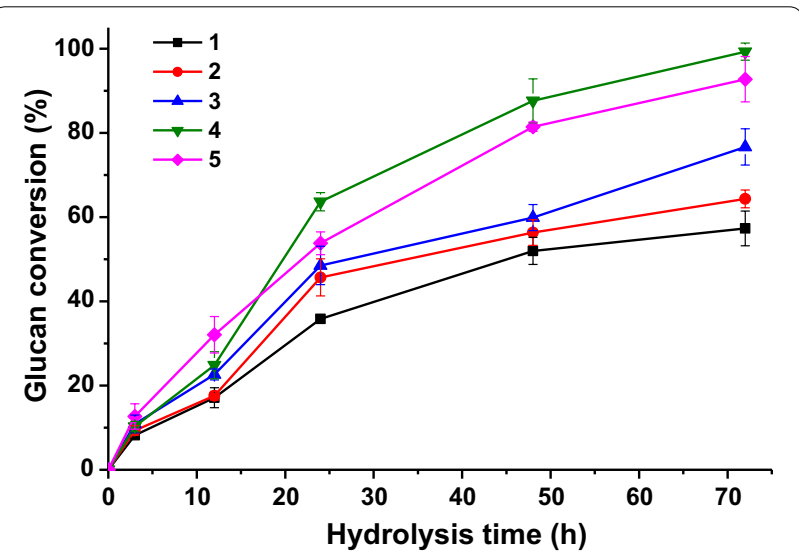

Fig. 4 Enzymatic hydrolysis of the acid-steam-exploded and the integrally treated corn stovers 
lignin content (10.7\%). XRD analysis showed that the $\mathrm{CrI}$ of Sample 4 was $42.4 \%$ and the cellulose was in a transition status from cellulose I to cellulose II, which implied that an apparent change in $\mathrm{CrI}$ (especially cellulose lattice transformation) had an important impact on the enzymatic hydrolysis of cellulose in addition to the lignin content. It has been reported that along with the transformation of cellulose I to cellulose II [36], the expansion of cellulose I lattice promotes the enzymatic hydrolysis of cellulose [35, 37, 38].

Besides, it was found that Sample 4 had a higher enzymatic hydrolysis rate than those of other samples after $24 \mathrm{~h}$. It was hypothesized that lignin was the main obstacle to cellulose degradation within the first $24 \mathrm{~h}$ when the degraded substrate was mainly amorphous cellulose. This is the reason why the initial rate of Sample 4 was lower than that of Sample 5 although more amorphous fractions were found in Sample 4. In fact, lignin is also a main factor for the increase of the material recalcitrance and decrease the enzymatic hydrolysis rate [39]. After $24 \mathrm{~h}$ of saccharification, the crystalline structure of cellulose in turn became the main obstacle to cellulose hydrolysis. The amorphous structure of the cellulose or cellulose II in Sample 4 made it more accessible to cellulase than those of other samples. Thus, the enzymatic hydrolysis rate of Sample 4 was higher than those of other samples after $24 \mathrm{~h}$, and the glucose yield of Sample 4 reached up to $99.3 \%$ in a relatively short period of hydrolysis. Overall, an alkaline ethanol system with appropriate $\mathrm{NaOH}$ concentration that is able to effectively remove lignin and change the crystalline structure of cellulose under moderate conditions represents a promising approach to modern biorefinery.

\section{Characterization of lignins}

The characterization of lignins obtained could facilitate the understanding of treatment process and reasonable utilization of the byproducts. It could be found that approximately $60 \%$ of lignin in the acid-steam-exploded corn stover was removed during $4 \%$ alcoholic $\mathrm{NaOH}$ post-treatment. The compositions of the lignin fraction (AL) released during the $4 \%$ alcoholic $\mathrm{NaOH}$ posttreatment and lignin-rich residue (EHR) remained after the enzymatic hydrolysis of the $4 \%$ alcoholic $\mathrm{NaOH}$ post-treated acid-steam-exploded corn stover are listed in Table 2. The relatively high purity (more than $80 \%$ ) of AL made this isolated lignin a good material for subsequent utilization. The utilization of AL in LPF resin preparation could be regarded as a component part of the integrated biorefinery of corn stover. The realization of this approach could help to overcome the limitation of byproducts dispose on economic benefit and production scale of corn stover biorefinery. Meanwhile, it could indirectly promote the extension of biorefinery industry toward energy and advanced materials. EHR was obtained via centrifugation followed by freeze-drying. It could be observed that the content of remained carbohydrates (3.82\%) in EHR was very low. The relatively high content of lignin in EHR (75.43\%) made it as an ideal material for LPF resin preparation. The remained cellulase, which was composed by protein, was also ideal material for wood adhesive production like lignin dose [40]. Thus, the EHR obtained was also potential material for LPF resin synthesis. The application of this hydrolysis residue could help to realize the whole component utilization of corn stover.

The two dimensional heteronuclear single-quantum correlation (2D HSQC) spectra of AL and purified EHR are given in Fig. 5 and the spectra were annotated with peak assignments based on previous publications [41, 42]. The structures of the identified lignin sub-units in the two lignins are also depicted in Fig. 5. In the sidechain region of the 2D HSQC spectra of AL, cross-signals of methoxyls $\left(\delta_{\mathrm{C}} / \delta_{\mathrm{H}} 55.9 / 3.73\right)$ and $\beta-O-4^{\prime}$ aryl ether linkages were the most prominent. The $\mathrm{C}_{\beta}-\mathrm{H}_{\beta}$ correlation in $\beta-O-4^{\prime}$ substructures (structure A) were observed at $\delta_{\mathrm{C}} / \delta_{\mathrm{H}} 72.2 / 4.86$. The $\mathrm{C}_{\beta}-\mathrm{H}_{\beta}$ correlations corresponding to the Syringyl-type $\beta-O-4^{\prime}$ substructures could be

Table 2 Compositional analysis of the isolated lignin fraction from the $4 \%$ alcoholic $\mathrm{NaOH}$ treatment producer and the corresponding enzymatic hydrolysis residue

\begin{tabular}{|c|c|c|c|c|c|c|c|c|c|}
\hline \multirow[t]{2}{*}{ Samples } & \multicolumn{2}{|c|}{ Lignin content (\%) } & \multicolumn{7}{|c|}{ Carbohydrate content (\%) } \\
\hline & AIL & ASL & Rha & Ara & Gal & Glc & Man & Xyl & GlcA/GalA \\
\hline$A L$ & $78.83(0.86)^{b}$ & $3.32(0.47)$ & $0.23(0.06)$ & $-{ }^{a}$ & - & $0.52(0.11)$ & - & $4.62(0.14)$ & - \\
\hline EHR & $71.83(0.48)$ & $3.60(0.75)$ & - & - & - & $2.64(0.14)$ & - & $0.86(0.02)$ & $0.32 /-(0.02 /-)$ \\
\hline
\end{tabular}

$A L$ alkaline lignin obtained from the $4 \%$ alcoholic $\mathrm{NaOH}$ post-treatment producer, $E H R$ lignin-rich residue remained after enzymatic hydrolysis of the $4 \%$ alcoholic $\mathrm{NaOH}$ post-treated acid-steam-exploded corn stover, AlL acid insoluble lignin, ASL acid soluble lignin, Rha rhamnose, Ara arabinose, Gal galactose, Glc glucose, Man mannose, Xyl xylose, GlcA glucuronic acid, GlaA galacturonic acid

a Not detected

b The value in parenthesis is standard deviation 
seen at $\delta_{\mathrm{C}} / \delta_{\mathrm{H}} 85.8 / 4.12$. It could be found that the intensities of the signals originated from $\beta-O-4^{\prime}$ substructures in the spectrum of AL were significantly lower than those of the native lignin from the untreated corn stover as detected by our previous work [43]. This indicated that most of the $\beta-O-4^{\prime}$ linkages in lignin macromolecule have been cleaved during the integrated treatment process. The signals of other substructures found in the spectrum of native lignin in untreated corn stover, such as resinol, phenylcoumaran, and spirodienone, were also absent in the spectrum of AL. The results indicated that lignin in acid-steam-exploded corn stover has been partially degraded and the moderate post-treatment conditions used in this study were competent for removing the lignins. However, it should be noted that the linkages between lignin units were hard to cleave during alkaline ethanol post-treatment in this study. The cleavage of $\beta$ $O-4^{\prime}$ and other side-chain linkages should mainly occur during ASE treatment [44].

Weak signals of $\beta-O-4^{\prime}$ and other side-chain linkages implied that the AL possessed low molecular weight and relatively high phenolic hydroxyl content. Therefore, AL should be a precious phenolic material for LPF resin synthesis. Furthermore, in the 2D HSQC spectra of AL, the signals arising from $\beta$-D-Xylp were evidently noted, with its $\mathrm{C}_{2}-\mathrm{H}_{2}, \mathrm{C}_{3}-\mathrm{H}_{3}, \mathrm{C}_{4}-\mathrm{H}_{4}$, and $\mathrm{C}_{5}-\mathrm{C}_{5}$ correlations at $\delta_{\mathrm{C}} / \delta_{\mathrm{H}} 72.7 / 2.89,73.6 / 3.22,75.5 / 3.59$, and $62.6 / 3.40$ and 3.72, respectively. This implied that a certain amount of xylans still remained in $\mathrm{AL}$, which was well consistent with the result obtained in carbohydrate analysis of $\mathrm{AL}$ (Table 2). Xylans were mainly covalently bonded with lignin via lignin-carbohydrate complex linkages [45], and thus they were inevitably removed along with the lignin during the alkaline ethanol post-treatment. The presence of these carbohydrates in AL may affect the performance of LPF resins prepared from the corresponding lignin fractions to some extent [46]. In the case of the purified EHR, a strong cross-signal of methoxyl was clearly found and other cross-signals of the side-chain linkages disappeared.

The main cross-signals in the aromatic region of the 2D-HSQC spectra of AL are assigned to the aromatic rings of the different lignin units ( $p$-hydroxyphenyl $(\mathrm{H})$, guaiacyl (G), and syringyl (S) units). Signals corresponding to $p$-coumarates (PCE) and ferulates (FA) were also observed in this spectrum with relatively low intensities. It should be mentioned that the presence of PCE and FA can also provide potential active sites (unsubstituted 3 or
5 positions of phenolic hydroxyl group) for further utilization, such as LPF resin preparation. In the case of the purified EHR, the cross-signals of S units were very weak, while the signals of $\mathrm{G}$ and $\mathrm{H}$ units were relatively strong. This indicated that the lignin fraction with a high content of S units was removed as AL during the $4 \%$ alcoholic $\mathrm{NaOH}$ post-treatment.

${ }^{31} \mathrm{P}$ NMR analysis involving phosphorylation of hydroxyl groups followed by quantitative analysis in the presence of an internal standard allows quantification of all $-\mathrm{OH}$ groups present in lignin. For this reason, the content of potential active sites of a lignin for application in LPF adhesive preparation can be obtained using ${ }^{31} \mathrm{P}$ NMR analysis [47]. The ${ }^{31} \mathrm{P}$ NMR spectrum of AL and the quantitative data on the distribution of the various $-\mathrm{OH}$ groups are shown in Fig. 6. The data showed that the content of non-condensed G- and $\mathrm{H}$-type phenolic - $\mathrm{OH}$ was 0.67 and $0.57 \mathrm{mmol} \mathrm{g}^{-1}$, respectively. The active number calculated based on these data was $1.81 \mathrm{mmol} \mathrm{g}^{-1}$, which was slightly higher than that of a technical lignin $\left(1.72 \mathrm{mmol} \mathrm{g}^{-1}\right)$ used in our previous study [47]. Therefore, the reactivity of AL could make it as an ideal material for LPF resin preparation. The poor solubility of purified EHR in solution of anhydrous pyridine and deuterated chloroform $(1.6: 1, \mathrm{v} / \mathrm{v})$ seriously impeded the ${ }^{31} \mathrm{P}$ NMR analysis of this sample. Thus, it was not performed in this study.

\section{LPF resin preparation}

The adhesive preparations of LPF resin using AL and EHR were both dark-brown aqueous solutions, and their specific properties are listed in Table 3. Both resins had relatively high solid content (above $50 \%$ ), which was favorable for forming a continuous bond line between the two cementing limiting surfaces. The viscosities of the ALPF and EHRPF obtained were 987.4 and $766.2 \mathrm{mPa} \mathrm{s}$, respectively. It is well known that the high viscosity of LPF resin will obviously bring problem in the application stage. Fortunately, due to the good water solubility of the synthesized resin products, their viscosity could be adjusted to an acceptable level using water without blemishing the performance of the final products. Similar conclusion has been reported in our previous study [48-50].

The bonding strength and formaldehyde emissions of the plywoods prepared with the two LPF resins are also listed in Table 3. It could be observed that the plywoods assembled with the two resins performed differently. Interestingly, the bonding strength of both plywoods

(See figure on next page.)

Fig. $52 \mathrm{D}^{13} \mathrm{C}^{-1} \mathrm{H}$ correlation (HSQC) spectra of AL and purified EHR (a Aliphatic region of AL; b Aromatic region of AL; c Aliphatic region of purified EHR; d Aromatic region of purified EHR. Key structural details of lignin: (A) $\beta$-O- $4^{\prime}$ aryl ether linkages; $(H)$ p-hydroxyphenyl units; $(G)$ guaiacyl units; $(S)$ syringyl units; (PCE) p-coumarates; (FA) ferulates; (X) $\beta$-D-Xylp) 


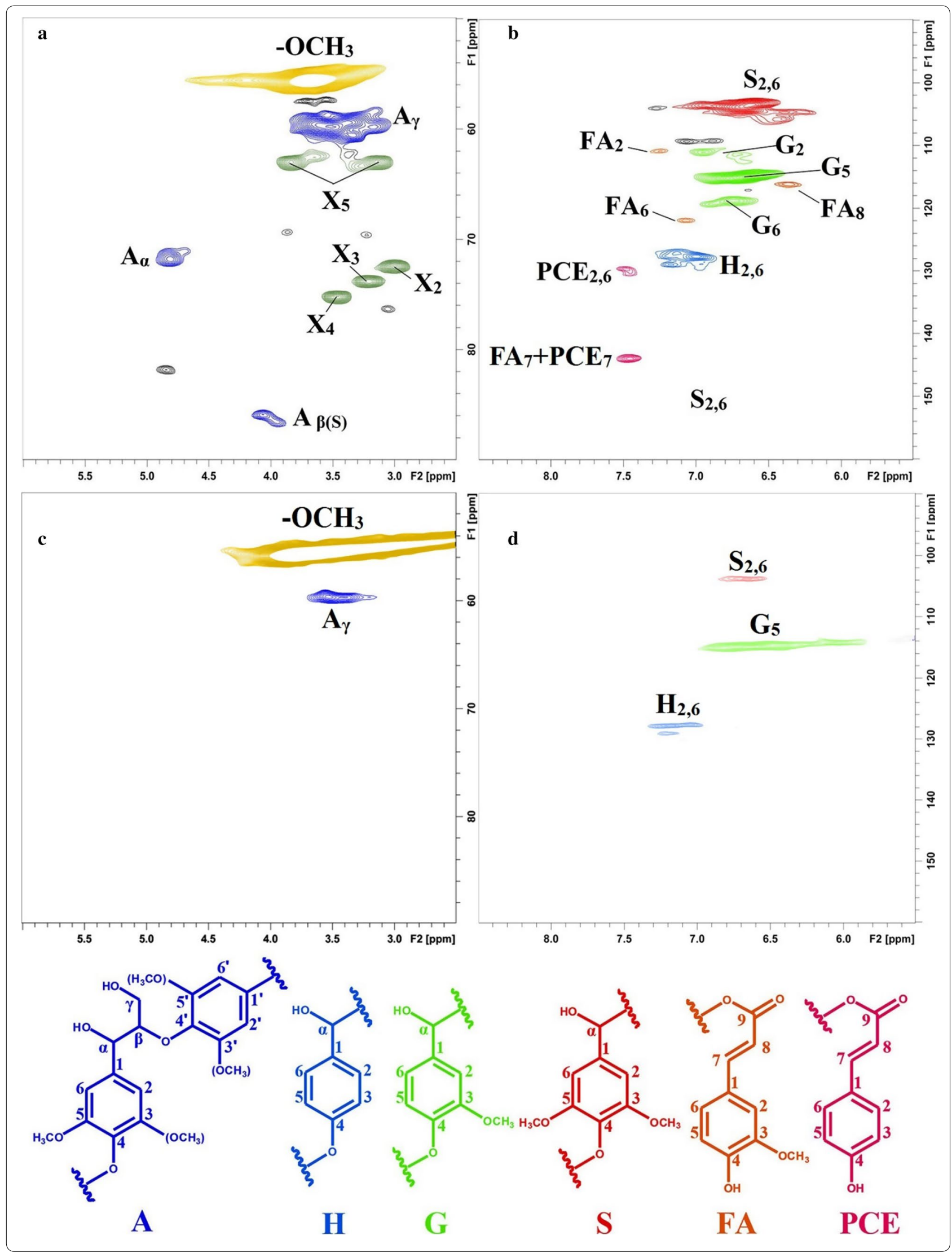




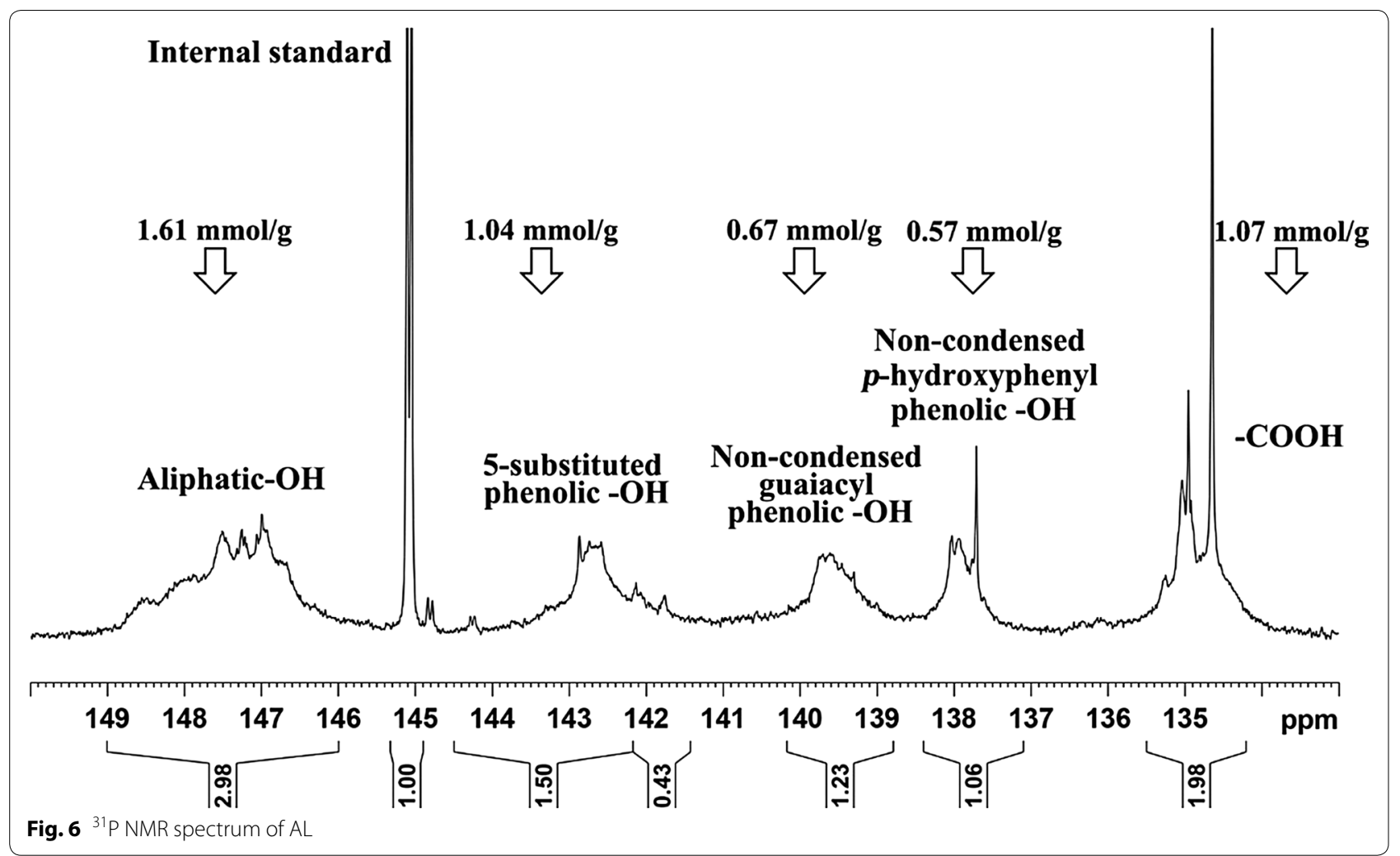

Table 3 The properties and plywood performances of lignin-phenol-formaldehyde (LPF) resin adhesives

\begin{tabular}{lllllll}
\hline Adhesives & \multicolumn{2}{l}{ Adhesive properties } & & \multicolumn{2}{l}{ Plywood performances } \\
\cline { 2 - 3 } & pH & Viscosity (mPa s) & Solid content (\%) & & Bonding strength (MPa) & Formaldehyde emission (mg L - $\left.^{-1}\right)$ \\
\hline ALPF & $11.8(0.6)^{c}$ & $987.4(1.58)$ & $51.3(0.44)$ & & $1.14(0.11)$ & $0.14(0.06)$ \\
EHRPF & $11.3(0.46)$ & $766.2(0.90)$ & $53.3(0.26)$ & & $1.01(0.17)$ & $0.21(0.02)$ \\
GB/T 14732-2006 & $\geq 7$ & $\geq 60$ & $\geq 35$ & $\geq 0.7$ & $\leq 0.5^{b}$ \\
\hline
\end{tabular}

ALPF lignin-phenol-formaldehyde resin adhesive prepared with $\mathrm{AL}$, EHRPF lignin-phenol-formaldehyde resin adhesive prepared with EHR

a GB/T 14732-2006: Wood adhesives: urea formaldehyde, phenol formaldehyde and melamine formaldehyde resins

b This requirement is defined by Chinese National Standard GB/T 9846.3-2004

c The value in parenthesis is standard deviation

(1.14 and 1.04 MPa for samples prepared with ALPF and EHRPF, respectively) met the standard for exterior-grade panels (first grade, $>0.7 \mathrm{MPa}$ ), and the formaldehyde emissions of the corresponding plywoods were all below $0.5 \mathrm{mg} \mathrm{L}^{-1}\left(0.14\right.$ and $0.21 \mathrm{mg} \mathrm{L}^{-1}$ for samples prepared with ALPF and EHRPF, respectively), meeting $E_{0}$ grade $\left(<0.5 \mathrm{mg} \mathrm{L}^{-1}\right)$ plywood requirements under Chinese National Standard GB/T 9846.3-2004 (Plywood-Part 3: General Specification for plywood for general use). It was also found that the performance of the plywoods prepared with either LPF were similar to that of the plywoods prepared with other LPF resins at the same lignin substitution level [50]. Thus, these two LPF resins could be utilized as low-toxicity wood adhesives to prepare both exterior plywood and interior $\mathrm{E}_{0}$-grade panels.

The data shown in Table 3 indicated that the LPF resins prepared in this study had good comprehensive performance. However, it should to be noted that a specific performance of the synthesized LPF resin could be adjusted according to the actual requirement. Such adjustment could be realized by changing the mole ratio of phenol to formaldehyde and the content of lignin or lignin-rich residue in the formulation, and consequently it promotes further improvement in the applicability of $\mathrm{AL}$ 
and EHR in LPF resin preparation. In addition, it should also be emphasized that the AL sample used to prepare LPF resins in this study was isolated and purified before resin synthesis. However, neither isolation nor purification of this lignin fraction was necessary for synthesizing LPF resin in a real industrial production scenario. A simple concentration process may be sufficient to obtain lignin solutions with desired solid content. For EHR, desiccation was unnecessary for their utilization in LPF resin preparation since water was also a common component of LPF resin. In fact, the application of EHR in this study inspired the valorization of fermentation residue obtained from bio-ethanol production. The remained yeast in the lignin-rich fermentation residues also contains a large proportion of protein, and may contribute to resin synthesis like cellulase dose. Thus, the lignin-rich fermentation residues can also be appropriate materials for LPF resin preparation.

\section{Conclusions}

An alkaline ethanol $\mathrm{NaOH}$ post-treatment under mild conditions was confirmed to be a very effective delignification method, and could effectively promote the cellulose digestibility of the acid-steam-exploded corn stover. It was found that the cellulose digestibility of the acid-steam-exploded corn stover post-treated with $4 \%$ alcoholic $\mathrm{NaOH}$ reached a maximum of $99.3 \%$, although 10.7\% lignin still remained. Except the lignin content of the acid-steam-exploded corn stover, an expansion of cellulose I lattice caused by the alkaline ethanol posttreatment also remarkably contributed to the enzymatic hydrolysis of cellulose. The lignin fractions (AL and EHR) obtained from $4 \%$ alcoholic $\mathrm{NaOH}$ post-treatment and subsequent enzymatic hydrolysis processes could be converted to high performance LPF resin adhesives, and the plywoods prepared with both LPF adhesives could meet the strength requirements of exterior plywood and limitation value of formaldehyde emissions for $\mathrm{E}_{0}$-grade panels. The proposed model for integral valorization of corn stover in this study has demonstrated a good application prospects and promotion of values.

\section{Methods}

\section{Materials}

An acid-steam-exploded corn stover was kindly supplied by a domestic cellulosic ethanol plant at the pilot scale in China. The specific parameters of the corn stover used in the pilot scale plant are not listed here, as they are considered a commercial secret. The acid-steam-exploded materials were washed thoroughly with water to remove all soluble substances, and then the solid residues were collected by filtration and oven-dried at $40{ }^{\circ} \mathrm{C}$ for $12 \mathrm{~h}$. The resultant materials, which served as raw materials for further testing in this study, were kept in a desiccator before delignification and analyses. Cellulast $1.5 \mathrm{~L}$ (cellulase, $70 \mathrm{FPU} \mathrm{g}^{-1}$ ) and Novozyme 188 ( $\beta$-glucosidase, 240 $\mathrm{CBU} \mathrm{g}{ }^{-1}$ ) were purchased from Novozymes Investment Co., Ltd. (Beijing, China). All chemicals used were of analytical grade unless otherwise noted.

\section{Delignification and enzymatic hydrolysis}

The acid-steam-exploded corn stovers were post-treated with $70 \%$ ethanol $(\mathrm{v} / \mathrm{v})$ containing certain amounts of $\mathrm{NaOH}(0.05,0.5$, and $4 \%)$ at $75{ }^{\circ} \mathrm{C}$ for $2 \mathrm{~h}$, respectively, in an airtight container. The solid to liquid ratio was 1: 20 $(\mathrm{w} / \mathrm{v})$ for each experiment. All the post-treated materials were filtered and thoroughly washed with distilled water until the wash was colorless and neutral in $\mathrm{pH}$, then dried at $40{ }^{\circ} \mathrm{C}$ for $12 \mathrm{~h}$ and stored in a desiccator before hydrolysis and analyses. To obtain an extensively delignified sample, an acid sodium chlorite delignification of the acid-steam-exploded corn stover was conducted according to the method reported by Hallac et al. [51]. The acidsteam-exploded corn stover samples obtained from 0.05 , 0.5 , and $4 \%$ alcoholic $\mathrm{NaOH}$ post-treatment, and acid sodium chlorite delignified sample were labeled as Sample $1,2,3,4$, and 5 , respectively. The detailed information of each sample is given in Table 1.

Enzymatic hydrolysis of the acid-steam-exploded corn stover and alkaline ethanol $\mathrm{NaOH}$ post-treated samples was performed in $50-\mathrm{mL}$ Erlenmeyer flasks at $50{ }^{\circ} \mathrm{C}$ in a shaking air bath at $150 \mathrm{rpm}$ for $72 \mathrm{~h}$. A typical hydrolysis mixture consisted of $0.1 \mathrm{~g}$ of sample, $5 \mathrm{~mL}$ sodium acetate buffer $(50 \mathrm{mM}, \mathrm{pH} 4.8)$ supplemented with $20 \mu \mathrm{L}$ antibiotics tetracycline and $10 \mu \mathrm{L}$ cycloheximide, and enzyme loading (17.5 FPU cellulase $\mathrm{g}^{-1}$ substrate) with a constant ratio of cellulase to $\beta$-glucosidase (1:2). After hydrolysis, $100 \mu \mathrm{L}$ sample was taken from the reaction mixture at certain intervals, deactivated in boiling water for $5 \mathrm{~min}$, then centrifuged for $10 \mathrm{~min}$ at 10,000 rpm, and stored at $-20^{\circ} \mathrm{C}$. The released glucose was also analyzed by high-performance anion exchange chromatography (HPAEC) system (Dionex ICS3000, US) equipped with a CarboPac PA 100 analytical column. A gradient solvent system was used as the mobile phase, consisting of ultrapure water, $\mathrm{NaOH}(0.25 \mathrm{M})$ and $\mathrm{NaAc}(1 \mathrm{M})$. The flow rate was adjusted to $0.4 \mathrm{~mL} \mathrm{~min}^{-1}$ and the volume injection was $20 \mu \mathrm{L}$ with a column temperature set at $30{ }^{\circ} \mathrm{C}$. All measurements were carried out in duplicate.

The lignin fraction in the effluent from the $4 \%$ alcoholic $\mathrm{NaOH}$ post-treatment (AL) was collected through acid $(\mathrm{pH}=2)$ precipitation after evaporating ethanol. The lignin-rich residue remained after the enzymatic hydrolysis of the $4 \%$ alcoholic $\mathrm{NaOH}$ post-treated acidsteam-exploded corn stover (EHR) was also collected via centrifugation followed by freeze-drying. For the 
2D HSQC NMR analysis, part of the lignin-rich residue remained after enzymatic hydrolysis was thoroughly washed with hot water to remove residual cellulase, and a purified EHR was recovered. Brief schematics for delignification and subsequent enzymatic hydrolysis processes are shown in Fig. 7.

\section{Compositional analysis}

The chemical compositions of the untreated corn stover, the acid-steam-exploded corn stover and the alkaline ethanol post-treated samples, AL as well as EHR were determined according to the National Renewable Energy Laboratory (NREL) protocol [52]. The total lignin content was the summation of acid-soluble lignin and acidinsoluble lignin. The sugars were quantified on a HPAEC system (Dionex ICS3000, US) equipped with a pulsed amperometric detector, an AS50 autosampler, a Carbopac TM PA-20 column $(4 \times 250 \mathrm{~mm}$, Dionex $)$, and a guard PA-20 column $(3 \times 30 \mathrm{~mm}$, Dionex $)$ according to a previously published method [41]. The sugar fractions were separated in a $5 \mathrm{mM} \mathrm{NaOH}$ isocratic (carbonate free and purged with nitrogen) condition for $20 \mathrm{~min}$, followed by a $0-75 \mathrm{mM} \mathrm{NaAc}$ gradient in $5 \mathrm{mM} \mathrm{NaOH}$ for $15 \mathrm{~min}$. Then the columns were washed with $200 \mathrm{mM}$ $\mathrm{NaOH}$ to remove carbonate for $10 \mathrm{~min}$, and followed a 5 min elution with $5 \mathrm{mM} \mathrm{NaOH}$ to re-equilibrate the column before the next injection. The total analysis time was $50 \mathrm{~min}$ and the flow rate was $0.4 \mathrm{~mL} \mathrm{~min}{ }^{-1}$. The analysis of sugar composition in the present study was run in duplicate.

\section{Characterization}

The acid-steam-exploded corn stover and alkaline ethanol post-treated samples were evaluated by FT-IR spectroscopy, which were obtained ranging from 4000 to $675 \mathrm{~cm}^{-1}$ under ATR mode using a Thermo Scientific Nicolet iN10 FTIR spectrometer (Thermo Nicolet Corporation, Madison, WI, USA) equipped with a liquid nitrogen-cooled MCT detector at room temperature. The solid-state $\mathrm{CP} / \mathrm{MAS}{ }^{13} \mathrm{C}$-NMR experiments were performed at $100 \mathrm{MHz}$ using a Bruker AV-III $400 \mathrm{M}$ spectrometer (Bruker, Karlsruhe, Germany). Each sample was

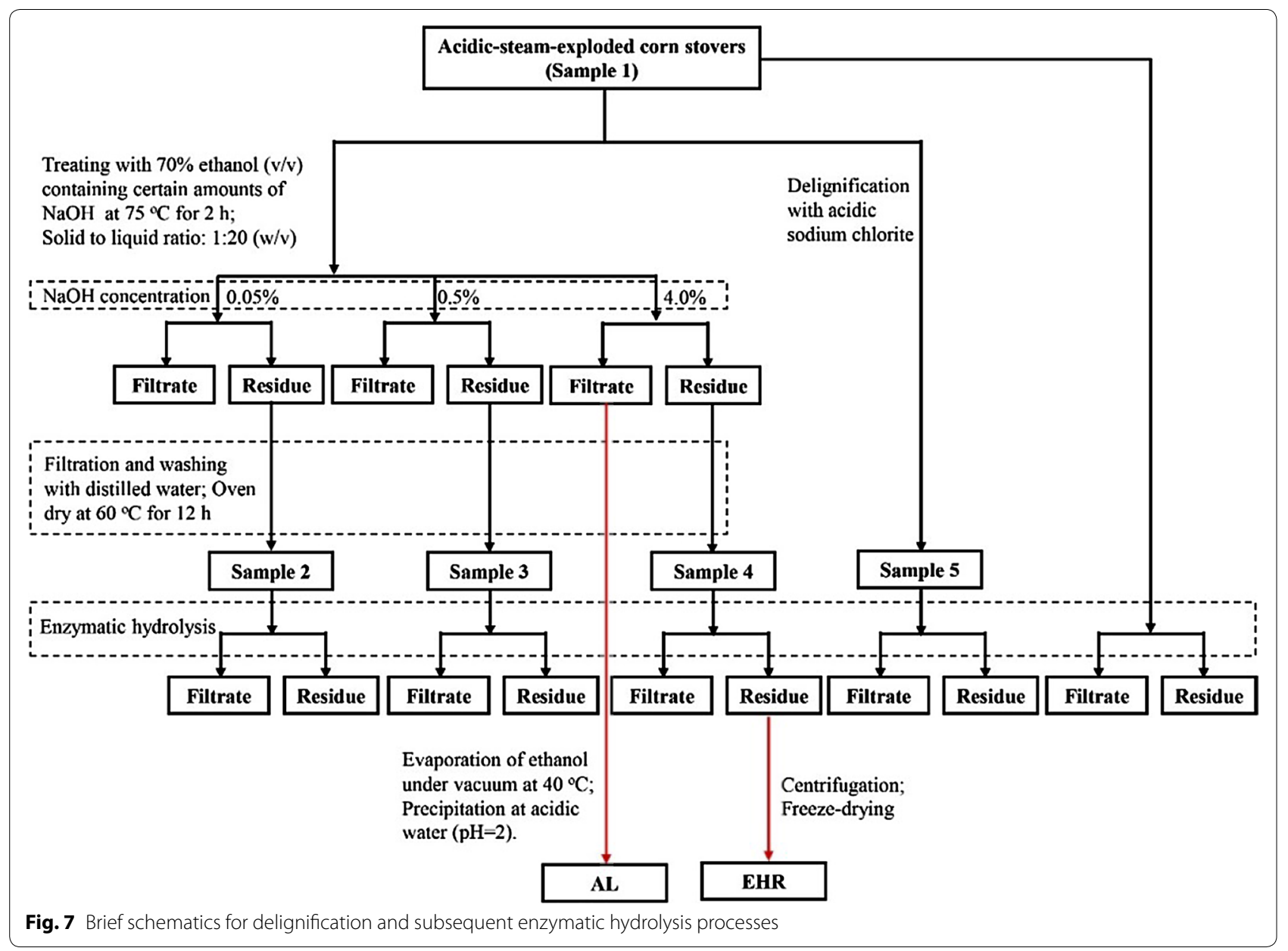


packed in a $4 \mathrm{~mm}$ zirconia rotor, then measured with a $\mathrm{CP}$ pulse program with $1 \mathrm{~ms}$ match time and $2 \mathrm{~s}$ delay between transients at spinning rate of $5 \mathrm{kHz}$. X-ray diffraction patterns of the samples were recorded on an XRD-6000 instrument (Shimadzu, Japan) ranging from 5 to $35^{\circ}$ of $2 \theta$ using a goniometer at a scanning speed of $2^{\circ}$ $\mathrm{min}^{-1}$. The scan was performed with Ni-filtered $\mathrm{Cu} \mathrm{K \alpha}$ radiation $(\lambda=1.54 \AA)$ at $40 \mathrm{kV}$ and $30 \mathrm{~mA}$, and the crystallinity index $(\mathrm{CrI})$ of the samples was calculated as the ratio of the area of the resolved crystalline peaks to the total area of a diffraction profile for $5-35^{\circ}$ based on the $\mathrm{X}$-ray diffraction curves of various samples. Structural features of the AL were investigated using 2D HSQC spectroscopy according to a method reported by a previous paper [53]. The 2D HSQC spectra were recorded at $25{ }^{\circ} \mathrm{C}$ on a Bruker AVIII $400 \mathrm{MHz}$ spectrometer. $80 \mathrm{mg}$ of lignin sample was dissolved in $0.5 \mathrm{~mL}$ of DMSO- $d_{6}$. The central solvent peak at $\delta_{\mathrm{C}} / \delta_{\mathrm{H}} 39.5 / 2.49$ was used as an internal reference. The spectral widths were 5000 and $20,000 \mathrm{~Hz}$ for the ${ }^{1} \mathrm{H}$ and ${ }^{13} \mathrm{C}$ dimensions, respectively. The number of collected complex points was 1024 for the ${ }^{1} \mathrm{H}$ dimension with a recycle delay of $1.5 \mathrm{~s}$. The number of transients was 64, and 256 time increments were always recorded in the ${ }^{13} \mathrm{C}$ dimension. The ${ }^{1} J_{\mathrm{CH}}$ used was $145 \mathrm{~Hz}$. Prior to Fourier transformation, the data matrices were zero filled to 1024 points in the ${ }^{13} \mathrm{C}$ dimension. The hydroxyl groups of AL were quantitatively analyzed by ${ }^{31} \mathrm{P}$ NMR technique. ${ }^{31} \mathrm{P}$ NMR spectrum was acquired after the reaction of lignin with 2-chloro-4, 4, 5, 5-tetramethyl-1, 3, 2-dioxaphospholane (TMDP). $20 \mathrm{mg}$ of lignin sample was dissolved in $500 \mu \mathrm{L}$ anhydrous pyridine and deuterated chloroform $(1.6: 1, \mathrm{v} / \mathrm{v})$ under stirring. Cholesterol and chromium (III) acetylacetonate were used as internal standard and relaxation reagent, respectively. TMDP was used as phosphorylating reagent. The parameters used in quantitative ${ }^{31} \mathrm{P}$ NMR experiment were listed as follows: $30^{\circ}$ pulse angle, $2 \mathrm{~s}$ relaxation delay $\left(d_{1}\right), 64 \mathrm{~K}$ data points and 1024 scans. The poor solubility of EHR (or purified EHR) in the solution of anhydrous pyridine and deuterated chloroform $(1.6: 1, \mathrm{v} / \mathrm{v})$ seriously impeded the ${ }^{31} \mathrm{P}$ NMR analysis of this sample. Thus, it was not conducted in this study.

\section{Lignin-phenol-formaldehyde resin preparation}

The lignin fractions (AL and EHR) obtained from the 4\% alcoholic $\mathrm{NaOH}$ integral biorefinery process were used to synthesize LPF resins (ALPF and EHRPF resins) using the same procedure as our previously reported study [50]. The substitution rate of lignin to phenol was set as $40 \%(\mathrm{w} / \mathrm{w})$ and the mole ratio of the phenol to formaldehyde was 1:1.8 for LPF resin preparation. Phenol and lignin were mixed in a three-necked flask followed by the addition of appropriate amount of $\mathrm{NaOH}$ solution (30 wt\%). The mixture was heated to $90{ }^{\circ} \mathrm{C}$ and held at the temperature for $1 \mathrm{~h}$. The temperature of the mixture was then dropped to $80^{\circ} \mathrm{C}$, and $70 \%$ of the total formaldehyde and $\mathrm{NaOH}$ solution (30 wt\%) was added. This mixture was kept at $80{ }^{\circ} \mathrm{C}$ for $1 \mathrm{~h}$. In sequence, the remaining 30\% of the total formaldehyde and $\mathrm{NaOH}$ solution (30 wt\%) was added, and that mixture was kept at $80{ }^{\circ} \mathrm{C}$ for $1 \mathrm{~h}$. Finally, the temperature of the mixture was decreased to $65{ }^{\circ} \mathrm{C}$, and the solution of $\mathrm{NaOH}(30 \mathrm{wt} \%)$ and urea $(5 \%$ of the total weight of phenol and lignin) was added. This mixture was held at $65^{\circ} \mathrm{C}$ for $30 \mathrm{~min}$. When the reaction was complete, it was rapidly cooled to $40{ }^{\circ} \mathrm{C}$ to yield the LPF resin. The $\mathrm{pH}$, viscosity, and nonvolatile content of the LPF resins were determined in accordance with the Chinese National Standard (GB/T 14704-2006: Testing methods for wood adhesives and their resins). The synthesized LPF resins were used as wood adhesive to prepare three-layer poplar plywoods $(400 * 400 * 4.5 \mathrm{~mm})$ by coating core poplar veneer with a $150 \mathrm{~g} \mathrm{~m}^{-2}$ adhesive on each side, then hot-pressing the plywoods at $145{ }^{\circ} \mathrm{C}$ under $1.0 \mathrm{MPa}$ for $7 \mathrm{~min}$. The bonding strength and formaldehyde emissions of the plywoods were measured according to the Chinese National Standard (GB/T 17657-2013: Testing methods of evaluating the properties of wood-based panels and surface decorated woodbased panels).

\section{Abbreviations \\ ASE: acid steam explosion; $\mathrm{NaOH}$ : sodium hydroxide; AL: the lignin fraction released during the $4 \%$ alcoholic $\mathrm{NaOH}$ post-treatment; EHR: lignin-rich resi- due remained after the enzymatic hydrolysis of the $4 \%$ alcoholic $\mathrm{NaOH}$ post- treated acid-steam-exploded corn stover; LPF: lignin-phenol-formaldehyde; FT-IR: Fourier transform infrared; CP/MAS ${ }^{13} \mathrm{C}-\mathrm{NMR}$ : cross polarization/magic angle spinning ${ }^{13} \mathrm{C}$ nuclear magnetic resonance; XRD: X-ray diffraction; $\mathrm{Crl}$ : crystallinity index; HPAEC: high-performance anion exchange chromatogra- phy; NREL: National Renewable Energy Laboratory; 2D HSQC: two dimensional heteronuclear single-quantum correlation; ALPF resin: LPF resin prepared with $A L ;$ EHRPF: LPF resin prepared with EHR.}

\section{Authors' contributions}

SY performed the major experiments, analyzed the data, and prepared the manuscript. YZ, WY and WW helped with the post-treatment experiments, analysis of samples and preparation of the LPF resins. YYW helped with the data analysis and manuscript preparation. TQY and RCS designed the project, supervised the experiments, and finalized the manuscript. All authors read and approved the final manuscript.

\section{Author details}

${ }^{1}$ Beijing Key Laboratory of Lignocellulosic Chemistry, Beijing Forestry University, Beijing 100083, People's Republic of China. ${ }^{2}$ Department of Chemical Engineering, University of Florida, Gainesville, FL 32603, USA. ${ }^{3}$ Textile Application, Research \& Development Center, Novozymes (China) Investment Co. Ltd, Beijing 100085, People's Republic of China. ${ }^{4}$ Department of Bioproducts and Biosystems Engineering, University of Minnesota, Saint Paul, MN 55108-6130, USA.

\section{Acknowledgements}

We are grateful for the financial support of this research from the Fundamental Research Funds for the Central Universities (2015ZCQ-CL-02, YX2015-03), the National Natural Science Foundation of China (31670587, 31430092), and Program of International S\&T Cooperation of China (2015DFG31860). 


\section{Competing interests}

The authors declare that they have no competing interests.

\section{Availability of supporting data}

All data generated or analyzed during this study are included within the article.

\section{Consent for publication}

All authors have approved the manuscript to be published.

\section{Funding}

Funding sources have been addressed in the Acknowledgements.

Received: 22 July 2016 Accepted: 25 October 2016

Published online: 08 November 2016

\section{References}

1. Himmel ME, Ding SY, Johnson DK, Adney WS, Nimlos MR, Brady JW, Foust TD. Biomass recalcitrance: engineering plants and enzymes for biofuels production. Science. 2007:315:804-7.

2. Sun Y, Zhuang JP, Lin L, Ouyang PK. Clean conversion of cellulose into fermentable glucose. Biotechnol Adv. 2009;27:625-32.

3. Pu Y, Zhang D, Singh PM, Ragauskas AJ. The new forestry biofuels sector. Biofuels Bioprod Bioref. 2007;2:58-73.

4. Zhao Y, Wang Y, Zhu J, Ragauskas A, Deng Y. Enhanced enzymatic hydrolysis of spruce by alkaline pretreatment at low temperature. Biotechnol Bioeng. 2008;99:1320-8.

5. Varga E, Réczey K, Zacchi G. Optimization of steam pretreatment of corn stover to enhance enzymatic digestibility. Appl Biochem Biotech. 2004;114:509-23.

6. Geng XL, Henderson WA. Pretreatment of corn stover by combining ionic liquid dissolution with alkali extraction. Biotechnol Bioeng. 2012;109:84-91.

7. Wang Z, Keshwani DR, Redding AP, Cheng JJ. Sodium hydroxide pretreatment and enzymatic hydrolysis of coastal Bermuda grass. Bioresour Technol. 2010;101:3583-5.

8. Kumar R, Wyman CE. Access of cellulase to cellulose and lignin for poplar solids produced by leading pretreatment technologies. Biotechnol Prog. 2009:25:807-19.

9. Vancov T, Mclntosh S. Alkali pretreatment of cereal crop residues for second-generation biofuels. Energy Fuels. 2011;25:2754-63.

10. Xu Z, Huang F. Pretreatment methods for bioethanol production. Appl Biochem Biotechnol. 2014;174:43-62.

11. Zhang J, Ma X, Yu J, Zhang X, Tan T. The effects of four different pretreatments on enzymatic hydrolysis of sweet sorghum bagasse. Bioresour Technol. 2011:102:4585-9.

12. Chen H, Zhao J, Hu T, Zhao X, Liu D. A comparison of several organosolv pretreatments for improving the enzymatic hydrolysis of wheat straw: substrate digestibility, fermentability and structural features. Appl Energy. 2015;150:224-32

13. Liu S. A synergetic pretreatment technology for woody biomass conversion. Appl Energy. 2015;144:114-28.

14. Kim SM, Dien BS, Singh V. Promise of combined hydrothermal/chemical and mechanical refining for pretreatment of woody and herbaceous biomass. Biotechnol Biofuels. 2016;9:97.

15. Zeng J, Tong Z, Wang L, Zhu J, Ingram L. Isolation and structural characterization of sugarcane bagasse lignin after dilute phosphoric acid plus steam explosion pretreatment and its effect on cellulose hydrolysis. Bioresour Technol. 2014;154:274-81.

16. Cavka A, Wallenius A, Alriksson B, Nilvebrant NO, Jönsson LJ. Ozone detoxification of steam-pretreated Norway spruce. Biotechnol Biofuels. 2015:8:196.

17. Wang L, Fan X, Tang P, Yuan Q. Xylitol fermentation using hemicellulose hydrolysate prepared by acid pre-impregnated steam explosion of corncob. J Chem Technol Biot. 2013;88:2067-74.

18. Kumar L, Arantes V, Chandra R, Saddler J. The lignin present in steam pretreated softwood binds enzymes and limits cellulose accessibility. Bioresour Technol. 2012:103:208-10.
19. Chen HZ, Liu LY. Unpolluted fractionation of wheat straw by steam explosion and ethanol extraction. Bioresour Technol. 2007:98:666-76.

20. Fan X, Cheng G, Zhang H, Li M, Wang S, Yuan Q. Effects of acid impregnated steam explosion process on xylose recovery and enzymatic conversion of cellulose in corncob. Carbohyd Polym. 2014;114:21-6.

21. Behera S, Arora R, Nandhagopal N, Kumar K. Importance of chemical pretreatment for bioconversion of lignocellulosic biomass. Renew Sust Energy Rev. 2014;36:91-106.

22. Singh J, Suhag M, Dhaka A. Augmented digestion of lignocellulose by steam explosion, acid and alkaline pretreatment methods: a review. Carbohyd Polym. 2015;117:624-31.

23. Zhang Z, Harrison MD, Rackemann DW, Doherty WO, O'Hara IM. Organosolv pretreatment of plant biomass for enhanced enzymatic saccharification. Green Chem. 2016;18:360-81.

24. Yue GJ, Wu GQ, Lin X. Insights into engineering of cellulosic ethanol. Chin J Biotech. 2014:30:1-12.

25. Monschein M, Nidetzky B. Effect of pretreatment severity in continuous steam explosion on enzymatic conversion of wheat straw: evidence from kinetic analysis of hydrolysis time courses. Bioresour Technol. 2016:200:287-96

26. Sun SL, Wen JL, Ma MG, Sun RC. Enhanced enzymatic digestibility of bamboo by a combined system of multiple steam explosion and alkaline treatments. Appl Energy. 2014;136:519-26.

27. Kobayashi N, Okada N, Hirakawa A, Sato T, Kobayashi J, Hatano S, Itaya Y, Mori S. Characteristics of solid residues obtained from hot-compressedwater treatment of woody biomass. Ind Eng Chem Res. 2009;48:373-9.

28. Kumar R, Mago G, Balan V, Wyman CE. Physical and chemical characterizations of corn stover and poplar solids resulting from leading pretreatment technologies. Bioresour Technol. 2009;100:3948-62.

29. De Rosa IM, Kenny JM, Maniruzzaman M, Moniruzzaman M, Monti M, Puglia D, Santulli C, Sarasini F. Effect of chemical treatments on the mechanical and thermal behaviour of okra (Abelmoschus esculentus) fibres. Compos Sci Technol. 2011:71:246-54.

30. Nuopponen MH, Wikberg HI, Birch GM, Jääskeläinen AS, Maunu SL, Vuorinen T, Stewart D. Characterization of 25 tropical hardwoods with Fourier transform infrared, ultraviolet resonance Raman, and ${ }^{13} \mathrm{C}-\mathrm{NMR}$ cross-polarization/magic-angle spinning spectroscopy. J Appl Polym Sci. 2006:102:810-9.

31. Brienzo M, Tyhoda L, Benjamin Y, Görgens J. Relationship between physicochemical properties and enzymatic hydrolysis of sugarcane bagasse varieties for bioethanol production. New Biotechnol. 2015;32:253-62.

32. Selig MJ, Viamajala S, Decker SR, Tucker MP, Himmel ME, Vinzant TB. Deposition of lignin droplets produced during dilute acid pretreatment of maize stems retards enzymatic hydrolysis of cellulose. Biotechnol Prog. 2007;23:1333-9.

33. Park S, Baker JO, Himmel ME, Parilla PA, Johnson DK. Cellulose crystallinity index: measurement techniques and their impact on interpreting cellulase performance. Biotechnol Biofuels. 2010;3:1.

34. Trache D, Donnot A, Khimeche K, Benelmir R, Brosse N. Physico-chemical properties and thermal stability of microcrystalline cellulose isolated from Alfa fibres. Carbohyd Polym. 2014;104:223-30.

35. Yuan TQ, Wang W, Xu F, Sun RC. Synergistic benefits of ionic liquid and alkaline pretreatments of poplar wood. Part 1: effect of integrated pretreatment on enzymatic hydrolysis. Bioresour Technol. 2013;144:429-34.

36. Wada M, Ike M, Tokuyasu K. Enzymatic hydrolysis of cellulose I is greatly accelerated via its conversion to the cellulose II hydrate form. Polym Degrad Stab. 2010;95:543-8.

37. Cheng G, Varanasi P, Li CL, Liu HB, Melnichenko YB, Simmons BA, Kent MS, Singh S. Transition of cellulose crystalline structure and surface morphology of biomass as a function of ionic liquid pretreatment and its relation to enzymatic hydrolysis. Biomacromolecules. 2011;12:933-41.

38. Yuan TQ, Wang W, Zhang LM, Xu F, Sun RC. Reconstitution of cellulose and lignin after $\left[\mathrm{C}_{2} \mathrm{mim}\right][\mathrm{OAc}]$ pretreatment and its relation to enzymatic hydrolysis. Biotechnol Bioeng. 2013;110:729-36.

39. Wallace J, Brienzo M, García-Aparicio MP, Görgens JF. Lignin enrichment and enzyme deactivation as the root cause of enzymatic hydrolysis slowdown of steam pretreated sugarcane bagasse. New Biotechnol. 2016:33:361-71.

40. Kumar R, Choudhary V, Mishra S, Varma IK, Mattiason B. Adhesives and plastics based on soy protein products. Ind Crop Prod. 2002;16:155-72. 
41. Del Rio JC, Rencoret J, Marques G, Li JB, Gellerstedt G, Jiménez-Barbero J, Martínez ÁT, Gutiérrez A. Structural characterization of the lignin from jute (Corchorus capsularis) fibers. J Agric Food Chem. 2009;57:10271-81.

42. Yuan TQ, Xu F, He J, Sun RC. Structural and physico-chemical characterization of hemicelluloses from ultrasound-assisted extractions of partially delignified fast-growing poplar wood through organic solvent and alkaline solutions. Biotechnol Adv. 2010;28:583-93.

43. Sun SN, Li MF, Yuan TQ, Xu F, Sun RC. Effect of ionic liquid/organic solvent pretreatment on the enzymatic hydrolysis of corncob for bioethanol production. Part 1: structural characterization of the lignins. Ind Crop Prod. 2013:43:570-7.

44. Li J, Gellerstedt G, Toven K. Steam explosion lignins; their extraction, structure and potential as feedstock for biodiesel and chemicals. Bioresour Technol. 2009;100:2556-61.

45. Yang S, Yuan TQ, Sun RC. Structural elucidation of whole lignin in cell walls of triploid of Populus tomentosa Carr. ACS Sustain Chem Eng. 2016;4:1006-15.

46. Wang G, Chen H. Carbohydrate elimination of alkaline-extracted lignin liquor by steam explosion and its methylolation for substitution of phenolic adhesive. Ind Crop Prod. 2014;53:93-101.

47. Yang $S, W u J Q$, Zhang Y, Yuan TQ, Sun RC. Preparation of lignin-phenolformaldehyde resin adhesive based on active sites of technical lignin. J Biobased Mater Bioenergy. 2015;9:266-72.
48. Zhang W, Ma Y, Xu Y, Wang C, Chu F. Lignocellulosic ethanol residuebased lignin-phenol-formaldehyde resin adhesive. Int J Adhes Adhes. 2013;40:11-8.

49. Zhao $M$, Jing J, Zhu $Y$, Yang $X$, Wang $X$, Wang Z. Preparation and performance of lignin-phenol-formaldehyde adhesives. Int J Adhes Adhes. 2016;64:163-7.

50. Yang S, Zhang Y, Yuan TQ, Sun RC. Lignin-phenol-formaldehyde resin adhesives prepared with biorefinery technical lignins. J Appl Polym Sci. 2015;132:36.

51. Hallac BB, Sannigrahi P, Pu Y, Ray M, Murphy RJ, Ragauskas AJ. Biomass characterization of Buddleja davidii: a potential feedstock for biofuel production. J Agric Food Chem. 2009;57:1275-81.

52. Sluiter A, Hames B, Ruiz R, Scarlata C, Sluiter J, Templeton D, Crocker D. Determination of structural carbohydrates and lignin in biomass. Golden: National Renewable Energy Laboratory; 2010. Report NTP-510-42618. 2011:17.

53. Yuan $T Q$, Sun $S N, X u$ F, Sun RC. Structural characterization of lignin from triploid of Populus tomentosa Carr. J Agric Food Chem. 2011;59:6605-15.

\section{Submit your next manuscript to BioMed Central and we will help you at every step:}

- We accept pre-submission inquiries

- Our selector tool helps you to find the most relevant journal

- We provide round the clock customer support

- Convenient online submission

- Thorough peer review

- Inclusion in PubMed and all major indexing services

- Maximum visibility for your research

Submit your manuscript at www.biomedcentral.com/submit 